\title{
Case Report Down's syndrome (Trisomy 21)
}

\author{
N. Harshithaa, G.Maragathavalli \\ Saveetha Dental College Ponamallee High Road Vellapanchavadi Chennai Tamilnadu,India \\ H.O.D And Professor Oral Medicine And Radiology Saveetha Dental College Ponamallee High Road \\ Vellapanchavadi Chennai Tamilnadu,India
}

\begin{abstract}
Downs syndrome is defined as a genetic disorder caused by the presence of all or a part of a third copy of chromosome 21. Downs syndrome is the most common chromosomal abnormality in humans. This article reports a case of downs syndrome in a $18 y$ r old female patient who came to SAVEETHA DENTAL COLLEGE describing the classical signs.

Key Words: Chromosome 21 trisomy, mental retardation, stunted growth
\end{abstract}

\section{Introduction:}

Downs syndrome is defined as a genetic disorder caused by the presence of all or a part of a third copy of chromosome 21. Downs syndrome is the most common chromosomal abnormality in humans. Downs syndrome was named after John Langdon Down,the British physician who described the syndrome in 1866. This syndrome is also known as Trisomy 21, named by Dr.Jecome Lejeune as a common chromosomal abnormality.

This syndrome is typically associated with physical growth delays, a particular set of facial characteristics and a severe degree of intellectual disability, which is apredominant characteristic found in all most all of them associated with this syndrome. This syndrome can be identified in a newborn by direct observation or in fetus by prenatal scanning.

\section{Case Report:}

Here, we present a 18yr old female patient who reported to SAVEETHA DENTAL COLLEGE with a compliant of mobilityof right upper anterior toothwhich has not exfoliated. Patient gave a history of pain in the same region for the last 5 days. On general examination, patient is short statured and mentally challenged. On extra oral examination, patient had saddle nose deformity, midface hypoplasia that is retruded maxilla and protruded mandible. Intraorally, retained retained decidious 52,54 , clinically missing 13 , high arch palate was present. Macroglossia with fissuring in the anterior $2 / 3^{\text {rd }}$ of the dorsum of tongue was seen.

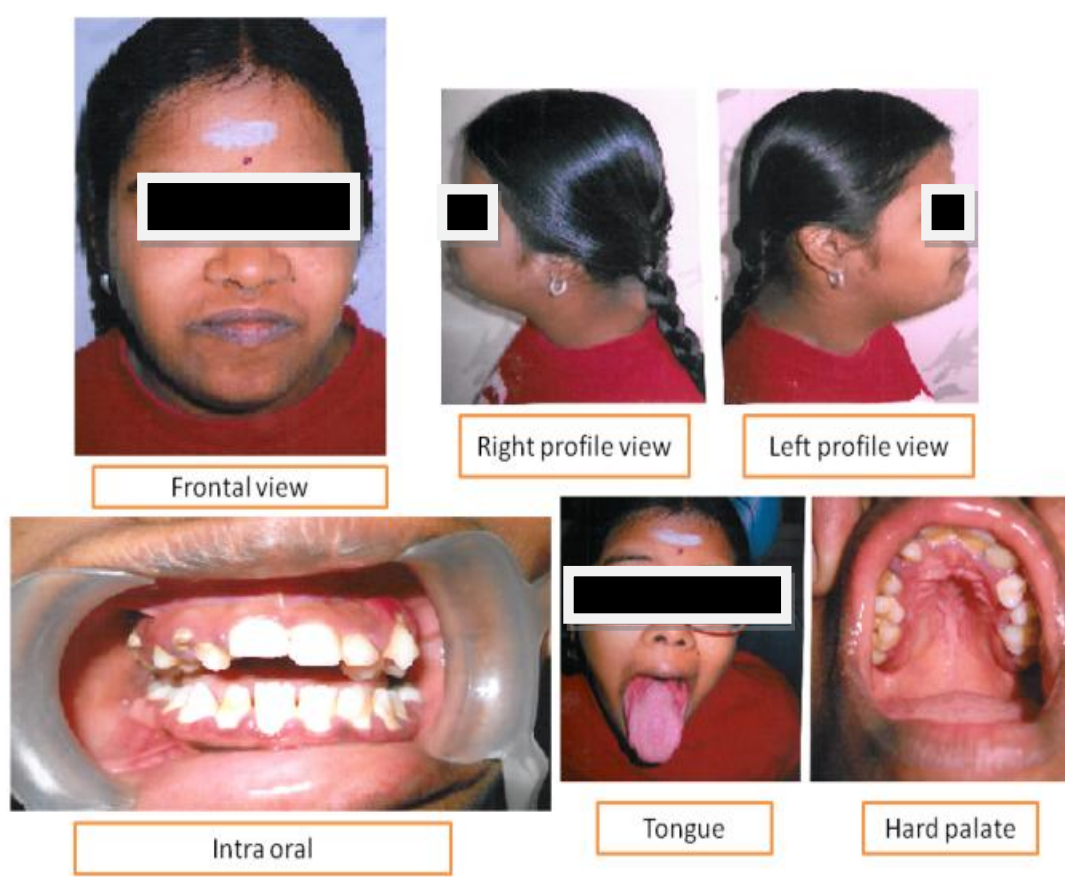




\section{Discussion :}

The signs and symptoms of Downs syndrome are charaterised by neotenization of brain and bodies.Management statergies such as Early childhood intervension,screening from common problems,medical treatment when indicated, a conductive family environment and vocational training can improve the overall development of children with Downs syndrome. Almost 99.8\%[1] of patients with Downs syndrome experience mental retardation and stunted growth. In 69\%[2] of high arched or oval palate is seen with 1-3\%[3] incidence of maxillary canine impaction, unilaterally[4]. Canine impaction was more prevalent among female patients[5]. This elevated figure can be attributed to an underdeveloped maxilla. In our case ,there were features like macroglossia ,a common characteristic [6]with fissuring in the anterior $2 / 3^{\text {rd }}$ of dorsum of tongue. Investigations including biochemical and serological were negative. OPG reveals the presence of impacted 13. Lateral cephalogram shows hypoplastic maxilla. This case was presented for its rarity and classical clinical presentation.

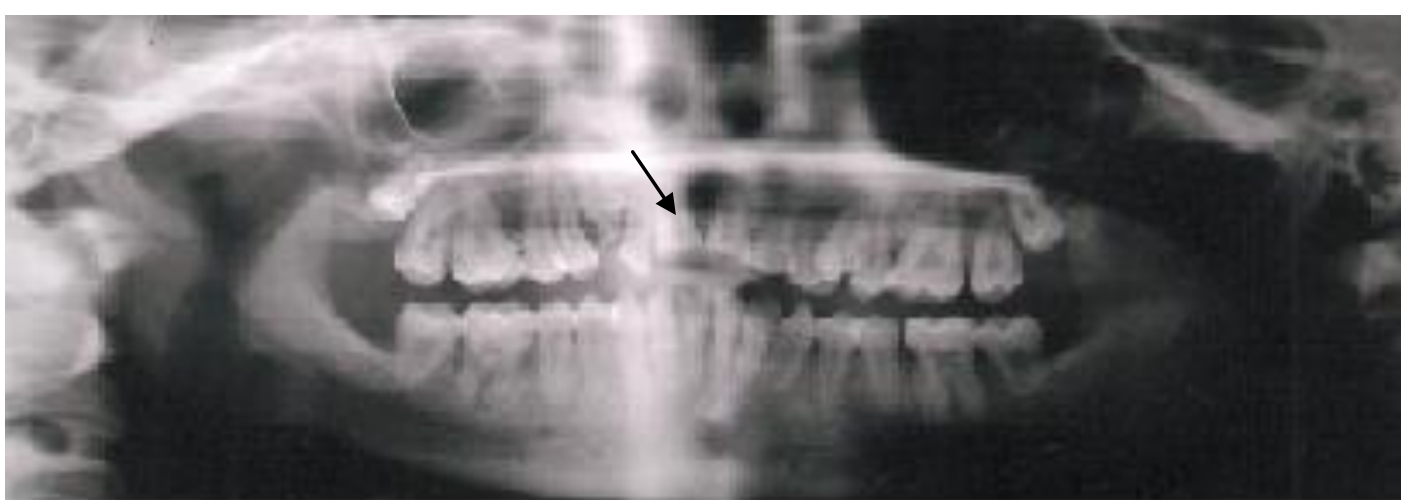

Ortho Pantamograph View

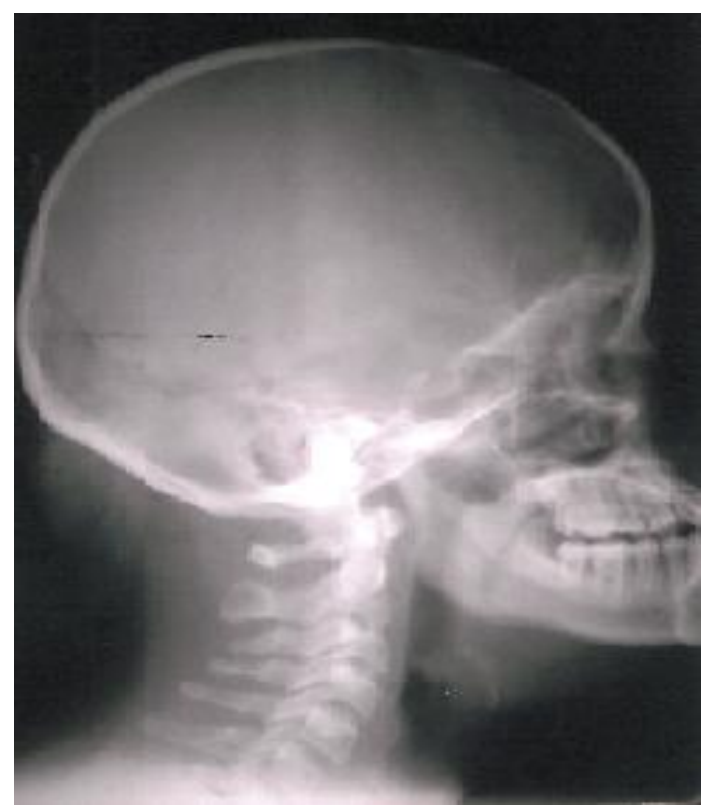

Lateral Ceph view

\section{References}

[1] American Academy of Pediatrics committee on genetics(February 2001).”American Acadamy of Pediatrics:Health supervision for children with Down syndrome".Pediatrics 107(2):442-49

[2] Burton L. Shapiro, Robert J. Gorlin , Robert S. Redman and Heinz h. Bruhl.The Palate and Down's Syndrome.The New England Journal of Medicine 1967: 276: 1460-1463

[3] Grover, P.S and L.Lorton. The incidence of unerupted permanent teeth and related clinical cases.Oral surgery Oral Med Oral Pathol 1985.59:420-425

[4] Oliver,R.G , J.E. Mannion, and J.M. Robinson. Morphology of maxillary lateral incisor in cases of unilateral impaction of the maxillary canine. Br J Orthod 1989. 16:9-16.

[5] Kramer,R.M. and A.D.Williams.The incidenceof impacted teeth. Oral surgery Oral Med Oral Pathol 1970.29:237-241

[6] Richards, M.C toward wholeness: Rudolf Steiner education in America. 1980. University Press of New England, N.H. 